\title{
Relationship between Escherichia coli virulence factors and postpartum metritis in dairy cows
}

\author{
F. N. Kassé, ${ }^{*}$ J. M. Fairbrother, ${ }^{*}$ and J. Dubuct ${ }^{1}$ \\ *OIE Reference Laboratory for Escherichia coli (EcL), Faculté de médecine vétérinaire, and \\ †Département de sciences cliniques, Faculté de médecine vétérinaire, Université de Montréal, C.P. 5000, St-Hyacinthe, QC, J2S 7C6, Canada
}

\begin{abstract}
The objectives of this study were to report the prevalence of Escherichia coli and Trueperella pyogenes in the uterus of postpartum dairy cows before the onset of postpartum metritis (PPM) and to quantify their association with subsequent occurrence of PPM, to quantify the association between the presence of genes encoding $E$. coli virulence factors (VF) and PPM, and to determine the accuracy of using early postpartum uterine bacteriology results (bacteria and VF) to identify cows at risk of PPM. A prospective cohort study was conducted on 3 commercial dairy farms. Uterine swabs were collected from 371 Holstein dairy cows (3 commercial herds) at 1 to $7 \mathrm{~d}$ in milk and submitted to the laboratory for identification of E. coli, T. pyogenes, and $E$. coli VF. A total of $40 \mathrm{VF}$ were tested using the radioactive probe hybridization method. Postpartum metritis was defined as the presence of a fetid watery red-brown uterine discharge, associated with fever (rectal temperature $>39.5^{\circ} \mathrm{C}$ ), and systemic signs of illness (dullness, reduced appetite, and milk production). Surveillance of PPM was done by trained farmers blinded to laboratory results and cows were followed until $21 \mathrm{~d}$ in milk. Statistical analyses were conducted using $2 \times$ 2 tables and mixed logistical regression models. Prevalences of E. coli, T. pyogenes, and PPM were 42, 34, and $15 \%$, respectively. A total of $32 \mathrm{VF}$ were found in $E$. coli isolates. Most prevalent VF were extraintestinal pathogenic genes such as fimH (89\%), hlyE (87\%), and iss $(70 \%)$. Cows positive for intrauterine $E$. coli were 3.2 times more likely to have subsequent PPM compared with bacteriologically negative cows. Cows with VF hra1 in their uterus were 2.7 times more likely to have PPM than cows positive for $E$. coli and negative for hra1 and 5.9 times more likely than bacteriologically negative cows. Cows with VF kpsMTII in their uterus were 3.2 times more likely to have PPM than
\end{abstract}

Received July 10, 2015.

Accepted February 9, 2016

${ }^{1}$ Corresponding author: jocelyn.dubuc@umontreal.ca cows positive for $E$. coli and negative for kpsMTII and 6.2 times more likely than bacteriologically negative cows. Using E. coli, hra1, and kpsMTII as predictors for subsequent PPM, positive predictive values were 23, 31 , and $42 \%$, respectively, whereas the negative predictive values were 91,80 , and $78 \%$, respectively. Overall, these results showed that E. coli and some VF were associated with PPM.

Key words: Escherichia coli, virulence factors, metritis, dairy cow

\section{INTRODUCTION}

A wide variety of bacterial species are present in the uterine lumen of dairy cows during early postpartum period (Jeon et al., 2015; Wagener et al., 2015). These include Escherichia coli, Trueperella pyogenes, streptococci, staphylococci, Pseudomonas spp., Clostridium spp., and various gram-negative anaerobes such as Fusobacterium necrophorum and Prevotella melaninogenica (Williams et al., 2005; Werner et al., 2012; Sens and Heuwieser, 2013; Wagener et al., 2014, 2015). The presence of these bacteria varies over time during the postpartum period and the overall population generally declines during the first $50 \mathrm{~d}$ after parturition (Sheldon et al., 2002). However, in a proportion of cows, some of these bacterial species persist in the uterine lumen and can favor the development of postpartum uterine diseases such as metritis and endometritis (Sheldon, 2004).

Postpartum metritis (PPM) is a severe inflammation of all layers of the uterus, (endometrium, submucosa, muscularis, and serosa) and is caused by a bacterial infection in the lumen of the uterus (Bondurant, 1999). The disease generally occurs during the first $21 \mathrm{~d}$ after parturition in dairy cattle and is defined by the presence of a fetid watery red-brown vaginal discharge with fever, body temperature being $>39.5^{\circ} \mathrm{C}$, and systemic signs of illness, such as dullness and anorexia (Drillich et al., 2001). Bacterial species frequently associated with the occurrence of PPM in dairy cows are E. coli and T. pyogenes (Sheldon et al., 2010; Werner et al., 
2012; Sens and Heuwieser, 2013; Wagener et al., 2014), and obligate anaerobes such as $F$. necrophorum and $P$. melaninogenicus (Williams et al., 2005). The specific role of each of these bacterial species in the pathogenesis of PPM is still not well understood. However, it has been suggested that $E$. coli could play an important role in this process as it is frequently found in the uterus in early postpartum period, and its presence has been associated with the increased prevalence of other bacterial species (Dohmen et al., 2000; Williams et al., 2007; Bicalho et al., 2012) and the occurrence of severe uterine lesions and subsequent infertility (Sheldon et al., 2002; Williams et al., 2007).

Some recent studies focused on intrauterine $E$. coli and demonstrated that the genes encoding certain $E$. coli virulence factors (VF), such as cdt, ast A, ibe A, hlyA, hlyE, fyuA, and fimH, are associated with PPM (Bicalho et al., 2010, 2012). It was suggested that the products of these genes may mediate induction of lesions in the uterine mucosa and promote the growth of opportunistic bacterial species, such as T. pyogenes and F. necrophorum, which would ultimately induce clinical signs of PPM (Bicalho et al., 2012). The disease was associated with negative effects in dairy cows, such as reduced milk production and lower reproductive performances (Toni et al., 2015; Piccardi et al., 2016).

Some studies have attempted to evaluate the beneficial effect of treating postpartum dairy cows to prevent PPM and avoid the impairment of productive and reproductive performances. Although Drillich et al. (2006) found that treating postpartum cows with metritis did not have a significant effect on milk production and reproductive performance, Risco and Hernandez (2003) revealed that treating postpartum cows affected by retained placenta significantly decreased the prevalence of subsequent PPM but did not improve subsequent reproductive performance. These results suggest that if a treatment is applied before the onset of clinical signs, PPM could potentially be prevented. Therefore, early identification of cows with high risk of developing PPM could help farmers to make a decision on whether or not to treat the cows. As E. coli colonizes the uterus immediately after parturition (Dohmen et al., 2000; Bicalho et al., 2012), and some E. coli VF have been associated with PPM (Bicalho et al., 2010, 2012), early identification of postpartum cows positive for intrauterine E. coli and positive for certain E. coli $\mathrm{VF}$ could inform on the risk level of cows for developing PPM.

Early postpartum uterine bacteriological analysis, including detection of $E$. coli $\mathrm{VF}$, is readily available to veterinary practitioners and could be used for early identification of high-risk cows. Unfortunately, few data are available to allow the validation of such an approach. Therefore, the objectives of this study were (1) to report the prevalence of E. coli and T. pyogenes in the uterus of postpartum dairy cows before the onset of PPM and quantify their association with subsequent occurrence of PPM, (2) to quantify the association between E. coli $\mathrm{VF}$ and the subsequent development of PPM, and (3) to determine the accuracy of using early postpartum uterine bacteriology results (bacteria and VF) to identify cows at risk of PPM.

\section{MATERIALS AND METHODS}

\section{Farm Selection and Sample Collection}

A prospective cohort study was conducted from November 2011 to June 2012 on 3 commercial Holstein dairy farms. Convenient farm selection was used and based on motivation of the farmers to diagnose and report uterine diseases, as well as on convenience of being located within $30 \mathrm{~km}$ of the bovine ambulatory clinic of the Faculté de médecine vétérinaire, Université de Montréal (St-Hyacinthe, QC, Canada). Participating herds had computerized health event records, and were enrolled on a biweekly (every other week) herd health veterinary program and a monthly testing of dairy herd improvement program. All farms had freestall housing for cows.

Farms were visited weekly by a research technician and a veterinarian. All sampling was done by the same research technician. During farm visits, all cows between 1 and $7 \mathrm{~d}$ after parturition that did not yet show clinical signs of PPM were sampled by the research technician. An estimated sample size of 360 cows was targeted for the study. Sample size calculation was based on objective 2 to find a significant difference (error $\alpha$ : $5 \%$; error $\beta: 20 \%)$ in PPM prevalence between cows carrying $E$. coli positive for a specific VF (PPM prevalence: $35 \%$ ) and those not carrying such E. coli (PPM prevalence: $15 \%$ ), and expecting a prevalence of $20 \%$ for this $\mathrm{VF}$ in the studied population. Enrolled cows were sampled once during the study. For uterine sampling, cows were restrained and the perineum was cleaned and disinfected with $70 \%$ ethyl alcohol solution (Isopropylic Alcohol $70 \%$ USP; Green Field Inc., Brampton, ON, Canada). A sterile double-guarded uterine swab (Guarded culture swab; Jorvet Inc., Loveland, CO) was introduced in the vagina until it reached the body of the uterus. The swab was then exposed to the dorsal aspect of the uterine wall and pulled back inside its sheath. The swab was then placed in an anaerobic transportation medium (BBL Port-A-Cult Tubes; Becton, Dickinson and Company, Sparks, MD) and kept at $4^{\circ} \mathrm{C}$ until submission to the veterinary diagnostic laboratory of the Université de Montréal within $12 \mathrm{~h}$ of collection. 
Procedures of sample collection were approved by the animal care committee of the Université de Montréal.

\section{Bacteria Isolation}

For isolation of $T$. pyogenes, uterine swabs were plated on Colombia blood agar (Oxoid, Ottawa, ON, Canada) and incubated aerobically at $35^{\circ} \mathrm{C}$ for $48 \mathrm{~h}$. Beta-hemolytic, catalase-negative minuscule colonies demonstrating gram-positive coryneform rods identified as T. pyogenes were isolated according to the PONBAC-019 procedure (McVey et al., 2013) commonly used in the veterinary diagnostic laboratory of the Université de Montréal. For isolation of $E$. coli, swabs were plated on blood agar and MacConkey agar (Oxoid) at $37^{\circ} \mathrm{C}$. At the World Organisation for Animal Health (OIE) Reference Laboratory for Escherichia coli (Faculté de médecine vétérinaire, Université de Montréal), 5 E. coli colonies from each positive uterine sample were streaked on blood agar for isolation and further identification. Isolates were submitted to indole spot, Simmons citrate, and motility tests, for confirmation of E. coli. Escherichia coli isolates were stored in tryptic soy broth containing $30 \%$ glycerol at $-80^{\circ} \mathrm{C}$ (Becton, Dickinson and Company) for further analysis.

\section{Identification of E. coli VF by Colony Hybridization}

Virulence factors were detected in isolates by colony hybridization using radioactively labeled $\left({ }^{32} \mathrm{P}\right)$ DNA probes. Procedures were performed according to the protocol of the OIE Reference Laboratory for Escherichia coli as described previously (Maluta et al., 2014; Fairbrother et al., 2015). Briefly, E. coli cultures in tryptic soy broth of the isolates were spotted onto Luria-Bertani agar and incubated at $37^{\circ} \mathrm{C}$ overnight. Colonies were then transferred to Whatman 541 filter paper (Whatman, Piscataway, NJ). The filter papers were processed, hybridized, and visualized by autoradiography.

Probes were derived from E. coli control strains by uniplex PCR, using the primers of the tested genes. After amplification, PCR products were purified and concentrated, using the QIAquick PCR Purification Kit (Qiagen, Hilden, Germany) according to manufacturer's instructions. After purification, probes were marked with phosphate $32\left({ }^{32} \mathrm{P}\right)$ using a specific kit (Amersham Ready to go DNA Labeling Beads, GE Healthcare UK Limited, Little Chalfont, UK), according to the manufacturer's instructions.

All selected E. coli isolates (5 isolates from each positive uterine sample) were examined for the presence of genes encoding $40 \mathrm{VF}$ using colony hybridization techniques. Some VF tested were those related to diarrheagenic E. coli pathotypes (ETEC, STEC, EPEC, EHEC), and others were related to extraintestinal pathogenic E. coli (ExpEC). Escherichia coli isolates having the same VF profile in a given sample were considered as the same isolate. The complete list of VF tested is available in Table A1.

\section{PPM Diagnosis}

Before the start of the study and every 3 mo during data collection, the definition of PPM was reviewed and standardized with participating farmers. Postpartum metritis was defined as the presence of a fetid watery red-brown uterine discharge, associated with fever (rectal temperature $>39.5^{\circ} \mathrm{C}$ ), and systemic signs of illness (dullness, reduced appetite, and milk production) within the first $21 \mathrm{~d}$ after parturition (Drillich et al., 2001). One person per farm was assigned the task to clinically diagnose PPM and to report it in individual health records. Farmers were blinded to laboratory results. When PPM was diagnosed, cows were treated based on the usual PPM treatment protocol, which was $5 \mathrm{~d}$ of ceftiofur IM SID $(2.2 \mathrm{mg} / \mathrm{kg}$; Zoetis Animal Health, Kirkland, QC, Canada) for all farms. If cows were diagnosed with PPM before uterine bacteriological swabbing, cows were not enrolled in the study.

\section{Statistical Analyses}

Statistical analyses were performed using SAS (version 9.3; SAS Institute Inc., Cary, NC). The experimental unit of the study was the cow and postpartum metritis was considered as the dependent variable. Individual data, such as parity and date of calving, were exported from the computerized record system into SAS. Cows were classified in 2 categories for parity groups: category 1 for primiparous and category 2 for multiparous. For calving season, cows that calved from November to February were classified as having calved during the winter season, whereas those which calved from March to June were classified as having calved in the spring season. Descriptive statistics were calculated using the FREQ procedure. Significance was declared when $P \leq 0.05$.

Univariable Analyses. Univariable analyses (Chisquared; FREQ procedure) were performed to screen for associations between (1) bacterial presence (E. coli and T. pyogenes) and PPM, and (2) E. coli VF and PPM. Variables with $P \leq 0.25$ were retained for multivariable modeling.

Association Between Bacterial Presence (E. coli and T. pyogenes) and PPM. Cows were 
grouped according to the presence or absence of each bacterial species. Univariable associations between PPM and bacterial species were tested.

Association Between E. coli VF and PPM. In this analysis, cows were classified in 3 categories: 0 included cows negative for $E$. coli, 1 included cows positive for $E$. coli and absence of $\mathrm{VF}$ in all $E$. coli isolates, and 2 included cows culture-positive for $E$. coli and with a VF was present in at least $1 \mathrm{E}$. coli isolate.

Multivariable Analyses. Multivariable logistic regression models (GLIMMIX procedure) were performed to evaluate the associations between prescreened $(P \leq$ 0.25 ) independent variables and PPM. One final model was built for bacterial species. Another final model was built for $E$. coli VF. The reference group for the latter was the group of cows negative for E. coli. A backward elimination strategy was used to build the final models until only variables with $P \leq 0.05$ were retained. A post-hoc Tukey-Kramer test was used to identify specific significant associations between all categories (cows negative for $E$. coli, cows positive for $E$. coli and negative for $\mathrm{VF}$, and cows positive for both $E$. coli and VF). All final models accounted for the effect of herd clustering (random effect) and parity group and season (forced variables). Finally, the accuracy of using final model predictors (bacterial species and VF) was calculated individually or in combination for predicting PPM using sensitivity, specificity, and positive and negative predictive values (FREQ procedure).

\section{RESULTS}

\section{Descriptive Statistics}

A total of 371 postpartum dairy cows were sampled and enrolled in this study. Samples were collected from 3 freestall farms with farm size ranging from 200 to 240 lactating cows $(117,150$, and 104 samples from farms 1, 2 and 3 , respectively). Sampled cows were primiparous $(\mathrm{n}=133 ; 36 \%)$ or multiparous $(\mathrm{n}=238 ; 64 \%)$ animals. Time after calving at which clinical signs of PPM were observed ranged from 3 to $20 \mathrm{~d}$, with an average of 7 $(\mathrm{SD} \pm 3)$ days. The overall prevalence of PPM in this study was $15 \%(\mathrm{n}=56)$; this prevalence was higher in primiparous cows $(24 \%)$ than in multiparous cows $(10 \% ; P<0.01)$. Cows that calved in the winter season also had higher prevalence of PPM (18\%) than cows that calved in the warm season $(10 \% ; P=0.03)$. Overall, $42 \%(\mathrm{n}=156)$ of uterine samples were positive for E. coli, $127(34 \%)$ of the samples were positive for $T$. pyogenes, and $42 \%(\mathrm{n}=157)$ of uterine samples were bacteriologically negative (Table 1 ).

A total of $32 \mathrm{VF}$ were identified in the $780 \mathrm{E}$. coli isolates. A total of 214 different VF profiles were identi- fied from $413 \mathrm{E}$. coli isolates. The number of VF present in any one isolate varied from 1 to 15 . Overall, the most prevalent VF among the $413 \mathrm{E}$. coli isolates were $\operatorname{fimH}(89 \% ; \mathrm{n}=367)$ and $h l y E(87 \% ; \mathrm{n}=359)$, which encode for bacterial adherence and hemolysin toxins, respectively. Other genes encoding for bacterial adhesions, such as hra1 (21\%; $\mathrm{n}=86)$ and papC (9\%; $\mathrm{n}=37$ ), were also found. Genes encoding virulence factors representing diarrheagenic E. coli (ETEC, EPEC, STEC) such as east1 $(17 \% ; \mathrm{n}=70)$, sta $(9 \% ; \mathrm{n}=$ 37), LT, F5, eae, stx1, stx2, and stb (0\%) were poorly represented. Isolates were positive for one or more $\mathrm{VF}$ representing ExpEC, such as sitA $(23 \% ; \mathrm{n}=95)$, fepC $(20 \% ; \mathrm{n}=82)$, irp2 $(11 \% ; \mathrm{n}=45)$, iutA and iucD $(15 \%$; $\mathrm{n}=61)$, and $c d t B(12 \% ; \mathrm{n}=49)$. A visual summary of the VF found in the uterine $E$. coli in the present study is shown in Figure 1.

\section{Univariable Associations}

Association Between Bacterial Species and $\boldsymbol{P P M}$. The prevalence of PPM in cows that were positive for E. coli $(23 \%)$ or T. pyogenes $(21 \%)$ at 1 to 7 DIM was higher than in cows bacteriologically negative $(10 \% ; P<0.01$; Table 2).

Association Between E. coli VF and PPM. All $32 \mathrm{VF}$ tested for univariable associations with PM had $P$-values $\leq 0.25$. All these variables were used for multivariable modeling.

\section{Multivariable Associations}

Multivariable Association Between Bacterial Species and PPM. Controlling for farm, season, and parity group effects, E. coli was the only bacterium associated with PPM. Cows infected with intrauterine E. coli at 1 to 7 DIM had 3.1 times (95\% CI: $1.7-5.9 ; P$ $<0.01)$ the odds of having PPM compared with cows that were bacteriologically negative at sampling. Least squares means of PPM from this association were $8.7 \%$ $(\mathrm{SEM}=3.3)$ and $23.1 \%(\mathrm{SEM}=7.0)$.

Multivariable Association Between E. coli VF and PPM. Controlling for herd, season, and parity group effects, the VF hra1 and kpsMTII were the only

Table 1. Bacterial species isolated from the uterus of Holstein dairy cows from 3 farms at 1 to 7 DIM

\begin{tabular}{lccc}
\hline $\begin{array}{l}\text { Farm } \\
\text { number }\end{array}$ & $\begin{array}{c}\text { Cow } \\
(\mathrm{n})\end{array}$ & $\begin{array}{c}\text { Escherichia coli } \\
{[\mathrm{n}(\% \text { by farm })]}\end{array}$ & $\begin{array}{c}\text { Trueperella pyogenes } \\
{[\mathrm{n}(\% \text { by farm })]}\end{array}$ \\
\hline 1 & 117 & $50(43)$ & $34(29)$ \\
2 & 150 & $64(43)$ & $57(38)$ \\
3 & 104 & $42(40)$ & $36(35)$ \\
Total & 371 & $156(42)$ & $127(34)$ \\
\hline
\end{tabular}




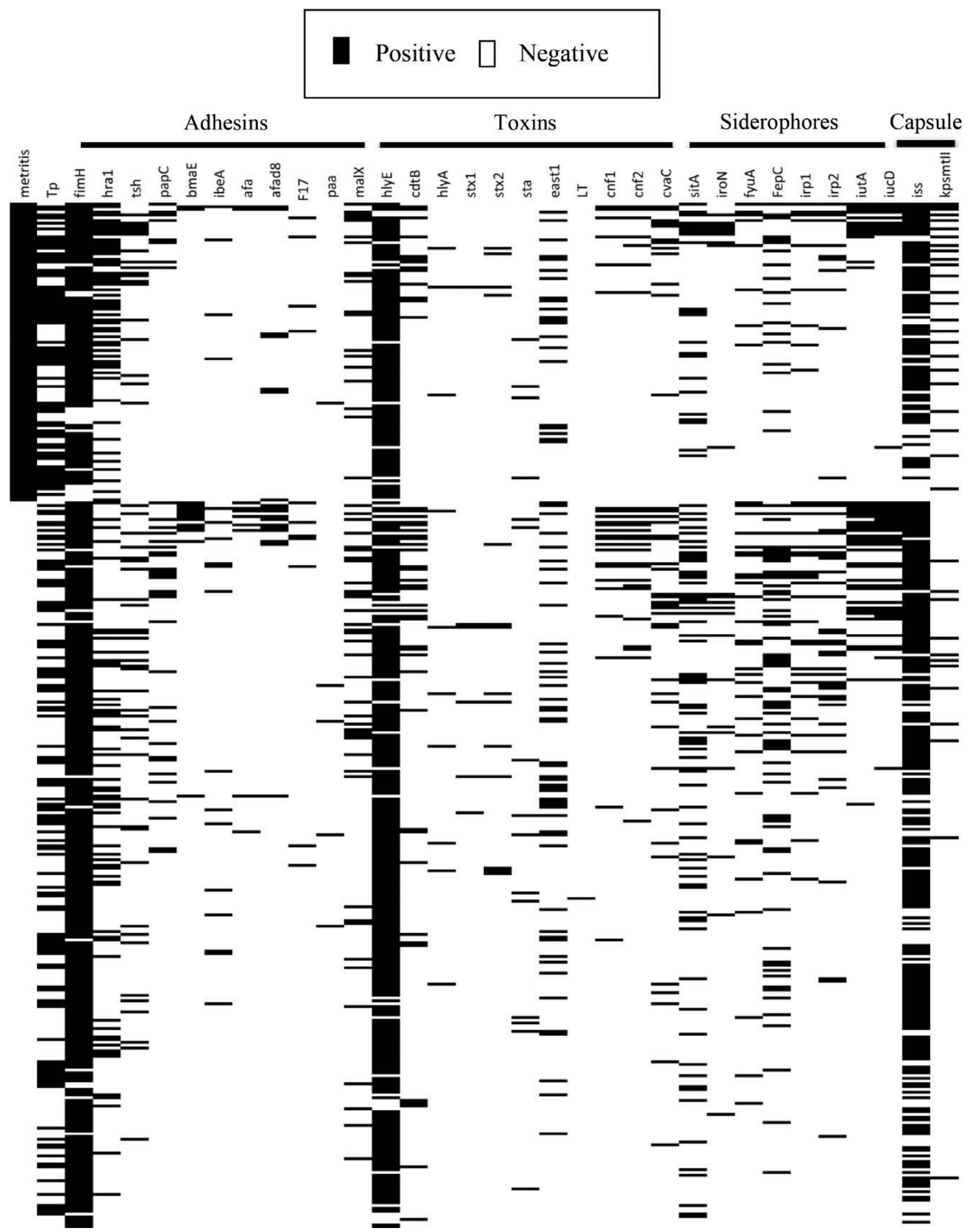

Figure 1. Presence of 32 virulence factors found in intrauterine Escherichia coli isolates from 163 Holstein dairy cows sampled at 1 to 7 DIM (figure is sorted by postpartum metritis status). $\mathrm{Tp}=$ Trueperella pyogenes . 


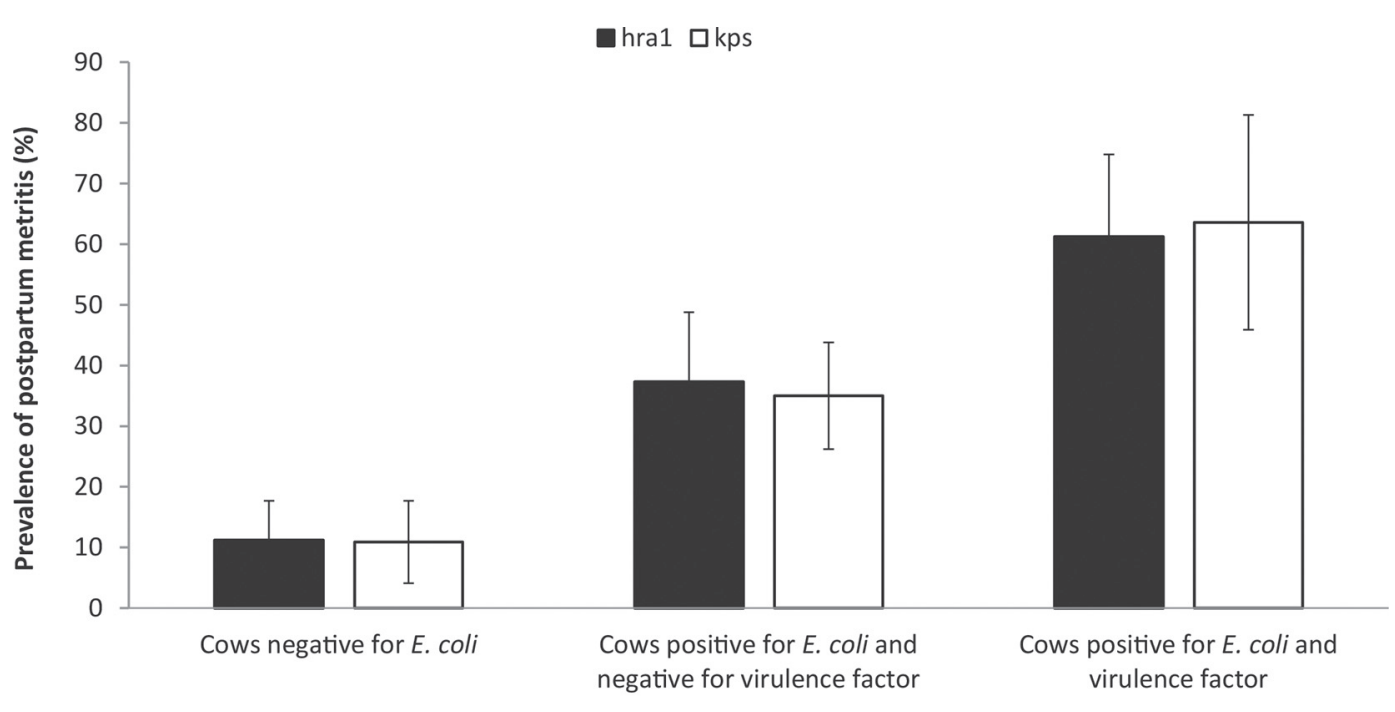

Bacterial uterine status at 1 to $\mathbf{7}$ days in milk

Figure 2. Least squares means $( \pm \mathrm{SEM})$ of postpartum metritis prevalence stratified by bacterial uterine status at 1 to 7 DIM in 371 Holstein dairy cows enrolled in an observational study.

variables associated with PPM that were retained in the final model. Cows positive for intrauterine $E$. coli carrying hra1 had 2.7 times (95\% CI: $1.3-6.4 ; P=0.02)$ the odds to be diagnosed with PPM than cows positive for E. coli that did not carry hra1 and 5.9 times (95\% CI: $2.7-10.2 ; P<0.01)$ the odds compared with cows negative for $E$. coli. Cows positive for intrauterine $E$. coli carrying kpsMTII had 3.2 times (95\% CI: 1.1-13.3; $P=0.04)$ the odds to be diagnosed with PPM than cows positive for $E$. coli that did not carry hra 1 and 6.2 times (95\% CI: $3.1-15.3 ; P<0.01$ ) the odds compared with cows negative for $E$. coli. Figure 2 presents the least squares means of PPM from this model.

The accuracy of finding E. coli, hra1, kpsMTII, or a combination of these VF to predict subsequent PPM was calculated. Our results showed that $31 \%$ of cows positive for intrauterine $E$. coli carrying hra 1 at 1 to 7 DIM developed PPM in wk 2 or 3 postpartum, whereas $80 \%$ of cows negative for intrauterine $E$. coli carrying hra1 did not develop PPM during this time period. For kpsMTII, $42 \%$ of cows positive for intrauterine $E$.

Table 2. Univariable association between the presence of bacterial species in the uterus of Holstein dairy cows at 1 to 7 DIM and the development of postpartum metritis

\begin{tabular}{lccc}
\hline Bacterial species & $\mathrm{n}$ & $\begin{array}{c}\text { Postpartum } \\
\text { metritis } \\
\text { prevalence }(\%)\end{array}$ & $P$-value \\
\hline Culture negative & 157 & 10 & Referent \\
Escherichia coli $^{1}$ & 156 & 23 & 0.01 \\
Trueperella pyogenes $^{1}$ & 127 & 21 & 0.01 \\
\hline
\end{tabular}

${ }^{1}$ These bacteria could be mixed with other pathogens. coli carrying kpsMTII developed PPM in the coming weeks, whereas $78 \%$ of cows negative for $k p s M T I I$ did not (Table 3).

\section{DISCUSSION}

The results of the present study showed that the presence of $E$. coli was associated with greater odds of developing PPM. More specifically, it showed that the presence of $E$. coli in the uterus of cows at 1 to 7 DIM increased by 3.1 times the odds of having subsequent PPM compared with negative cows in the multivariable analysis after accounting for the effects of farm, season, and parity group. These results were expected and consistent with some previous publications (Sheldon et al., 2010; Werner et al., 2012; Sens and Heuwieser, 2013; Wagener et al., 2014). However, they differ from the ones reported by Santos et al. (2011) and Jeon et al. (2015), who did not find any association between $E$. coli and PPM using metagenomic analysis. Nonetheless, it is important to keep in mind that these 2 studies compared intrauterine bacterial species, including some that are uncultivable in a traditional laboratory from 2 distinct groups of cows, one with PPM and the other without PPM. In our study, standard microbiology culture procedures were used, which may explain this discrepancy with metagenomics studies, as some uncultivable bacteria might have stronger relationships with PPM than E. coli. Also, sampling for T. pyogenes at only one time point between 1 and 7 DIM might not be ideal because the uterine flora changes over time (Williams et al., 2005, 2007). It is also important to keep 
Table 3. Sensitivity (Se), specificity (Sp), positive predictive value (PPV), and negative predictive value (NPV) of finding at 1 to 7 DIM intrauterine Escherichia coli and the virulence factors kpsMTII and hra1 or a combination of these virulence factors to predict postpartum metritis in 371 Holstein dairy cows ${ }^{1}$

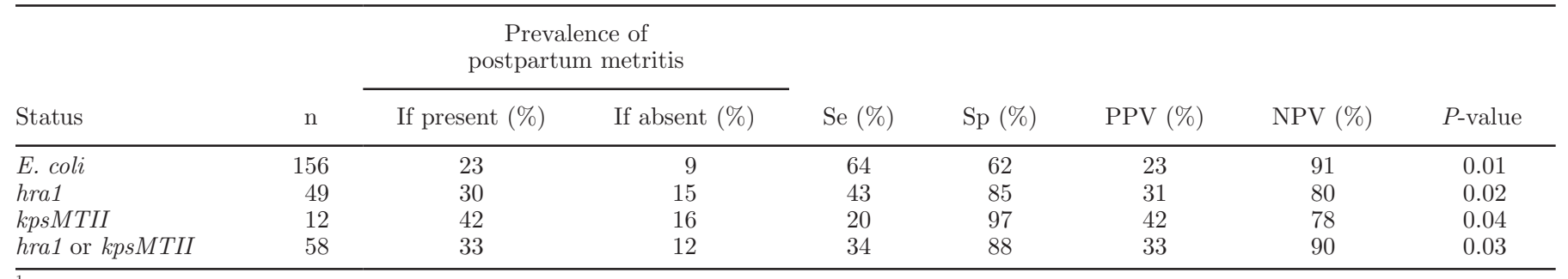

${ }^{1}$ The concomitant presence of $k p s M T I I$ and hra1 was not found in the data.

in mind that $E$. coli isolate identification was based on having the same VF combination in a sample obtained from the same cows. This method is not perfect and cannot allow confirmation with certainty that the isolates were genetically identical. The use of fingerprint PCR would have been a better approach to confirm that 2 isolates were identical. However, it could not be performed in the present study because of financial restriction. It seems unlikely that this situation could have biased our results but it cannot be excluded.

Several studies have attempted to elucidate the etiological role of $E$. coli in the development of PPM. Silva et al. (2009) tested 15 VF on intrauterine E. coli and found no association with PPM for any of the VF tested. Sheldon et al. (2010) tested 17 VF, including kpsMTII, and found no association with PPM. In contrast, Bicalho et al. (2010) evaluated 32 E. coli VF in intrauterine $E$. coli isolates and found that 6 of them (fim H, hlyA, cdt, kpsMII, ibeA, and astA) were associated with PPM. In the present study, all these VF were tested and only hra 1 and kpsMTII were associated with PPM in the final model. It was surprising not to find an association between the presence of fim $\mathrm{H}$ and PPM, as this had already been reported (Bicalho et al., 2010, 2012). Statistical power issues could potentially explain why some of the VF identified in the Bicalho et al. (2010) study were not found in the present study. The prevalence of fimH was high (89\%) in the present study, and perhaps having a greater number of cows positive for $E$. coli and negative for fimH would have given different results. Another possibility could be that VF distribution varies between herds and regions; because all published studies used a smaller number of herds (Silva et al., 2009; Bicalho et al., 2010; Sheldon et al., 2010) for conducting their investigations, it may lead to inconsistent associations with PPM. Conducting such studies in a smaller number of herds is ideal from a study management perspective, as it improves the quality of sampling and PPM disease definition used on farms. However, this strategy could lead to potential biases, such as not having representative samples of $\mathrm{VF}$ for the general population of dairy herds. The fact that PPM diagnosis in the present study was done by trained farmers and not confirmed by veterinarians could also have influenced the study results. This is certainly a weakness of the current study, but doing otherwise was unrealistic when conducting a field study involving multiple herds. Only one person per farm was trained and charged with doing PPM surveillance to reduce this effect. But, veterinarians or not, it has also been shown that intra- and interobserver reliability for smell, color, and viscosity is relatively poor and that sensorial assessment of vaginal discharge is subjective (Sannmann and Heuwieser, 2015). Future studies should investigate $\mathrm{VF}$ in large-scale studies involving a large number of herds, using trained veterinarians to diagnose PPM, and trying to quantify intra- and interobserver agreement if more than one person is involved in the diagnostic process. Therefore, it is important to keep in mind that our study results do not deny the previously reported importance of fim $\mathrm{H}$ in the pathogenesis of PPM as fim $H$ encodes for type 1 pili containing the fim $H$ adhesion, which is present in the majority of $E$. coli isolates (Langermann et al., 1997). Sheldon et al. (2010) also concluded that endometrial pathogenic $E$. coli were expressing the fim $H$ gene because mannose treatment of $E$. coli isolates decreased their ability to adhere to endometrial cells.

As previously described, kpsMTII was associated with PPM in the present study. This gene encodes for the capsular proteins $\mathrm{K} 1$ or $\mathrm{K} 5$, allowing bacteria to escape phagocytosis. The presence of kpsMTII has been associated with cellulitis in chickens (de Brito et al., 2003) and urinary tract infections in women (Moreno et al., 2005, 2009). Recently, the presence of kpsMTII was also found to be associated with PPM in dairy cows (Bicalho et al., 2010); therefore, it was not surprising to find an association between this VF and PPM in our study. More specifically, kpsMTII was found in $13 \%$ of cows that developed PPM in the present study, being comparable to the prevalence of $12.5 \%$ reported by Bicalho et al. (2010). 
Another VF associated with PPM in the present study was hra1, which encodes for the heat-resistantagglutinin 1 located on the outer membrane of the bacteria. Although this finding is novel in the dairy cow, it is not surprising considering its potential effect in humans. Its role in colonization and its virulence was shown in neonatal meningitis E. coli strain RS218 (Fagan and Smith, 2007). The presence of this gene is sufficient to confer agglutination of human erythrocytes, bacterial autoaggregation, enhanced biofilm formation, aggregative adherence, and invasion of epithelial cells (Mancini et al., 2011). Recently, hra1 was also found in enteroaggregative $E$. coli isolated from humans (Bhargava et al., 2009). It seems highly plausible that hra1 allows bacterial autoaggregation, leading to the formation of large aggregates of bacteria that cannot be phagocytized. This gene could also enhance formation of biofilms that persist on the uterine mucosa. Further studies are needed to confirm this hypothesis.

Although kpsMTII and hra1 were associated with PPM, the detection of these genes in the early postpartum period only conferred relatively low positive predictive values $(<42 \%)$, which may seem inappropriate if using this gene-detection strategy to identify cows that will develop subsequent PPM. However, our results suggest that not finding these $2 \mathrm{VF}$ during the first week postpartum can provide high specificity and high negative predictive values. It is important to keep in mind that PPM is a complex multifactorial disease in which several factors are involved, including uterine bacterial contamination but also immune response to this infection. For farms located relatively close to a diagnostic laboratory, sampling all cows $1 \mathrm{~d}$ after calving and submitting this sample to the laboratory for determining whether E. coli, hra1, kpsMTII, or other VF identified by previous studies are present could potentially help farmers to identify early and quite accurately cows at low risk of PPM. Subsequently, the rest of the cows could be considered at higher risk of PPM and a surveillance strategy for diagnosis of PPM could be implemented. In the short term, the presence of $E$. coli in the uterus of dairy cows could be identified early using on-farm mastitis bacteriological culture kits. In the long term, development of a specific diagnostic kit for VF can be envisaged, but future research and technology development need to be done in this area. It is also important to keep in mind that finding cows early at high risk for PPM would be even more helpful to farmers if a proven prevention treatment strategy could be used. Current literature on this specific approach is currently lacking, but a study investigating a treatment prevention strategy for PPM reported some benefits when using retained placenta as the criteria for identi- fying cows at high or low risk (Risco and Hernandez, 2003). Future research focusing on disease prevention and also on prudent use of antibiotics should be done before implementing such an approach. Future research should also confirm the test accuracy performance found in the present study, as the numbers of cows positive for hra1 and kpsMTII were relatively small.

\section{CONCLUSIONS}

The presence E. coli in the uterine lumen of dairy cows during early postpartum period was associated with greater odds of subsequent PPM in dairy cows. Similarly, some E. coli VF, such as hra1 and kpsMTII, were also associated with greater odds of PPM. Although using the presence of these bacteria or VF for predicting subsequent PPM in dairy cows yielded relatively low positive predictive values, their absence from the uterus was more accurate to identify cows at low risk of PPM.

\section{ACKNOWLEDGMENTS}

This work was supported by the "Programme de Soutien à l'Innovation en Agroalimentaire" (PSIA) from the "Ministère de l'Agriculture, des Pêcheries et de l'Alimentation du Québec" (grant number : 810144; Québec, QC, Canada). The authors wish to thank Brigitte Lehoux, Ghyslaine Vanier, and Jean Philippe Pelletier (Faculté de médecine vétérinaire, Université de Montréal, St-Hyacinthe, QC, Canada) for their technical assistance.

\section{REFERENCES}

An, H., J. M. Fairbrother, C. Desautels, and J. Harel. 1999. Distribution of a novel locus called Paa (porcine attaching and effacing associated) among enteric Escherichia coli. Adv. Exp. Med. Biol. 473:179-184.

Bauer, R. J., L. Zhang, B. Foxman, A. Siitonen, M. E. Jantunen, H. Saxen, and C. F. Marrs. 2002. Molecular epidemiology of 3 putative virulence genes for Escherichia coli urinary tract infectionusp, iha, and iroN (E. coli). J. Infect. Dis. 185:1521-1524.

Beaudry, M., C. Zhu, J. M. Fairbrother, and J. Harel. 1996. Genotypic and phenotypic characterization of Escherichia coli isolates from dogs manifesting attaching and effacing lesions. J. Clin. Microbiol. 34:144-148.

Bhargava, S., B. B. Johnson, J. Hwang, T. A. Harris, A. S. George, A. Muir, J. Dorff, and I. N. Okeke. 2009. Heat-resistant agglutinin 1 is an accessory enteroaggregative Escherichia coli colonization factor. J. Bacteriol. 191:4934-4942.

Bicalho, M. L. S., V. S. Machado, G. Oikonomou, R. O. Gilbert, and R. C. Bicalho. 2012. Association between virulence factors of Escherichia coli, Fusobacterium necrophorum, and Arcanobacterium pyogenes and uterine diseases of dairy cows. Vet. Microbiol. 157:125-131.

Bicalho, R. C., V. S. Machado, M. L. S. Bicalho, R. O. Gilbert, A. G. V. Teixeira, L. S. Caixeta, and R. V. V. Pereira. 2010. Molecular 
and epidemiological characterization of bovine intrauterine Escherichia coli. J. Dairy Sci. 93:5818-5830.

Bondurant, R. H. 1999. Inflammation in the bovine female reproductive tract. J. Anim. Sci. 77(Suppl 2):101-110.

Chapman, T. A., X. Y. Wu, I. Barchia, K. A. Bettelheim, S. Driesen D. Trott, M. Wilson, and J. J. Chin. 2006. Comparison of virulence gene profiles of Escherichia coli strains isolated from healthy and diarrheic swine. Appl. Environ. Microbiol. 72:4782-4795.

Cid, D., R. Sanz, I. Marin, H. de Greve, J. A. Ruiz-Santa-Quiteria, R. Amils, and R. de la Fuente. 1999. Characterization of nonenterotoxigenic Escherichia coli strains producing F17 fimbriae isolated from diarrheic lambs and goat kids. J. Clin. Microbiol. $37: 1370-1375$.

Daigle, F., J. Harel, J. M. Fairbrother, and P. Lebel. 1994. Expression and detection of pap-, sfa-, and afa-encoded fimbrial adhesin systems among uropathogenic Escherichia coli. Can. J. Microbiol. 40:286-291.

de Brito, B. G., L. C. Gaziri, and M. C. Vidotto. 2003. Virulence factors and clonal relationships among Escherichia coli strains isolated from broiler chickens with cellulitis. Infect. Immun. 71:4175-4177.

Dohmen, M. J. W., K. Joop, A. Sturk, P. E. J. Bols, and J. A. C. M. Lohuis. 2000. Relationship between intra-uterine bacterial contamination, endotoxin levels and the development of endometritis in postpartum cows with dystocia or retained placenta. Theriogenology 54:1019-1032.

Dozois, C. M., M. Dho-Moulin, A. Bree, J. M. Fairbrother, C. Desautels, and R. Curtiss 3rd.. 2000. Relationship between the Tsh autotransporter and pathogenicity of avian Escherichia coli and localization and analysis of the Tsh genetic region. Infect. Immun. 68:4145-4154.

Drillich, M., O. Beetz, A. Pfützner, M. Sabin, H. J. Sabin, P. Kutzer, H. Nattermann, and W. Heuwieser. 2001. Evaluation of a systemic antibiotic treatment of toxic puerperal metritis in dairy cows. J. Dairy Sci. 84:2010-2017.

Drillich, M., U. Reichert, M. Mahlstedt, and W. Heuwieser. 2006. Comparison of two strategies for systemic antibiotic treatment of dairy cows with retained fetal membranes: Preventive vs. selective treatment. J. Dairy Sci. 89:1502-1508.

Ewers, C., G. Li, H. Wilking, S. Kiessling, K. Alt, E. M. Antao, C Laturnus, I. Diehl, S. Glodde, T. Homeier, U. Bohnke, H. Steinruck, H. C. Philipp, and L. H. Wieler. 2007. Avian pathogenic, uropathogenic, and newborn meningitis-causing Escherichia coli: How closely related are they? Int. J. Med. Microbiol. 297:163-176.

Fagan, R. P., and S. G. Smith. 2007. The Hek outer membrane protein of Escherichia coli is an auto-aggregating adhesin and invasin. FEMS Microbiol. Lett. 269:248-255.

Fairbrother, J. H., S. Dufour, J. M. Fairbrother, D. Francoz, E. Nadeau, and S. Messier. 2015. Characterization of persistent and transient Escherichia coli isolates recovered from clinical mastitis episodes in dairy cows. Vet. Microbiol. 176:126-133.

Furrer, B., U. Candrian, and J. Luthy. 1990. Detection and identification of $E$. coli producing heat-labile enterotoxin type I by enzymatic amplification of a specific DNA fragment. Lett. Appl. Microbiol. $10: 31-34$.

Girardeau, J. P., Y. Bertin, C. Martin, M. Der Vartanian, and C. Boeuf. 1991. Sequence analysis of the clpG gene, which codes for surface antigen CS31A subunit: Evidence of an evolutionary relationship between CS31A, K88, and F41 subunit genes. J. Bacteriol. 173:7673-7683.

Goluszko, P., S. L. Moseley, L. D. Truong, A. Kaul, J. R. Williford, R. Selvarangan, S. Nowicki, and B. Nowicki. 1997. Development of experimental model of chronic pyelonephritis with Escherichia coli O75:K5:H-bearing Dr fimbriae: Mutation in the dra region prevented tubulointerstitial nephritis. J. Clin. Invest. 99:1662-1672.

Herrero, M., V. de Lorenzo, and J. B. Neilands. 1988. Nucleotide sequence of the $i u c D$ gene of the pColV-K30 aerobactin operon and topology of its product studied with $p h o A$ and lacZ gene fusions. J. Bacteriol. 170:56-64.

Hilali, F., R. Ruimy, P. Saulnier, C. Barnabe, C. Lebouguenec, M. Tibayrenc, and A. Andremont. 2000. Prevalence of virulence genes and clonality in Escherichia coli strains that cause bacteremia in cancer patients. Infect. Immun. 68:3983-3989.

Jeon, S. J., A. Vieira-Neto, M. Gobikrushanth, R. Daetz, R. D. Mingoti, A. C. Parize, S. L. de Freitas, A. N. da Costa, R. C. Bicalho, S. Lima, K. C. Jeong, and K. N. Galvao. 2015. Uterine microbiota progression from calving until establishment of metritis in dairy cows. Appl. Environ. Microbiol. 81:6324-6332.

Karch, H., S. Schubert, D. Zhang, W. Zhang, H. Schmidt, T. Olschlager, and J. Hacker. 1999. A genomic island, termed high-pathogenicity island, is present in certain non-O157 Shiga toxin-producing Escherichia coli clonal lineages. Infect. Immun. 67:5994-6001.

Langermann, S., S. Palaszynski, M. Barnhart, G. Auguste, J. S. Pinkner, J. Burlein, P. Barren, S. Koenig, S. Leath, C. H. Jones, and S. J. Hultgren. 1997. Prevention of mucosal Escherichia coli infection by FimH-adhesin-based systemic vaccination. Science 276:607-611.

Lortie, L. A., J. D. Dubreuil, and J. Harel. 1991. Characterization of Escherichia coli strains producing heat-stable enterotoxin b (STb) isolated from humans with diarrhea. J. Clin. Microbiol. 29:656659.

Maluta, R. P., J. M. Fairbrother, A. E. Stella, E. C. Rigobelo, R. Marinez, and F. A. de Avila. 2014. Potentially pathogenic Escherichia coli in healthy, pasture-raised sheep on farms and at the abattoir in Brazil. Vet. Microbiol. 169:89-95.

Mancini, J., B. Weckselblatt, Y. K. Chung, J. C. Durante, S. Andelman, J. Glaubman, J. D. Dorff, S. Bhargava, R. S. Lijek, K. P. Unger, and I. N. Okeke. 2011. The heat- resistant agglutinin family includes a novel adhesin from enteroaggregative Escherichia coli strain 60A. J. Bacteriol. 193:4813-4820.

McVey, D. S., M. Kennedy, and M. M. Chengappa. 2013. Veterinary Microbiology. 3rd ed. Chapter 28, page 203. John Wiley and Sons Inc., Ames, IA.

Moreno, E., J. R. Johnson, T. Perez, G. Prats, M. A. Kuskowski, and A. Andreu. 2009. Structure and urovirulence characteristics of the fecal Escherichia coli population among healthy women. Microbes Infect. 11:274-280.

Moreno, E., I. Planells, G. Prats, A. M. Planes, G. Moreno, and A. Andreu. 2005. Comparative study of Escherichia coli virulence determinants in strains causing urinary tract bacteremia versus strains causing pyelonephritis and other sources of bacteremia. Diagn. Microbiol. Infect. Dis. 53:93-99.

Ngeleka, M., J. Pritchard, G. Appleyard, D. M. Middleton, and J. M. Fairbrother. 2003. Isolation and association of Escherichia coli AIDA-I/STb, rather than EAST1 pathotype, with diarrhea in piglets and antibiotic sensitivity of isolates. J. Vet. Diagn. Invest. $15: 242-252$.

Ojeniyi, B., P. Ahrens, and A. Meyling. 1994. Detection of fimbrial and toxin genes in Escherichia coli and their prevalence in piglets with diarrhoea. The application of colony hybridization assay, polymerase chain reaction and phenotypic assays. Zentralbl. Veterinarmed. B. 41:49-59.

Oswald, E., M. Tabouret, R. Boivin, and J. De Rycke. 1994. Detection of Escherichia coli strains producing cytotoxic necrotizing factor type two (CNF2) by enzyme-linked immunosorbent assay. Vet. Microbiol. 40:209-218.

Piccardi, M., G. Romero, G. Veneranda, E. Castello, D. Romero, M. Balzarini, and G. A. Bó. 2016. Effect of puerperal metritis on reproductive and productive performance in dairy cows in Argentina. Theriogenology 85:887-893.

Risco, C. A., and J. Hernandez. 2003. Comparison of ceftiofur hydrochloride and estradiol cypionate for metritis prevention and reproductive performance in dairy cows affected with retained fetal membranes. Theriogenology 60:47-58.

Rodriguez-Siek, K. E., C. W. Giddings, C. Doetkott, T. J. Johnson, and L. K. Nolan. 2005. Characterizing the APEC pathotype. Vet. Res. 36:241-256.

Sandhu, K. S., R. C. Clarke, and C. L. Gyles. 1997. Hemolysin phenotypes and genotypes of eaeA-positive and eaeA-negative bovine verotoxigenic Escherichia coli. Adv. Exp. Med. Biol. 412:295-302.

Sannmann, I., and W. Heuwieser. 2015. Technical note: Intraobserver, interobserver, and test-retest reliabilities of an assessment of vagi- 
nal discharge from cows with and without acute puerperal metritis. J. Dairy Sci. 98:5460-5466.

Santos, T. M. A., R. O. Gilbert, and R. C. Bicalho. 2011. Metagenomic analysis of the uterine bacterial microbiota in healthy and metritic postpartum dairy cows. J. Dairy Sci. 94:291-302.

Savarino, S. J., A. Fasano, J. Watson, B. M. Martin, M. M. Levine, S. Guandalini, and P. Guerry. 1993. Enteroaggregative Escherichio coli heat-stable enterotoxin 1 represents another subfamily of $\mathrm{E}$. coli heat-stable toxin. Proc. Natl. Acad. Sci. USA 90:3093-3097.

Sens, A., and W. Heuwieser. 2013. Presence of Escherichia coli, Trueperella pyogenes, $\alpha$-hemolytic streptococci, and coagulase-negative staphylococci and prevalence of subclinical endometritis. J. Dairy Sci. 96:6347-6354.

Sheldon, I. M. 2004. The postpartum uterus. Vet. Clin. North Am. Food Anim. Pract. 20:569-591.

Sheldon, I. M., D. E. Noakes, A. N. Rycroft, D. U. Pfeiffer, and H. Dobson. 2002. Influence of uterine bacterial contamination after parturition on ovarian dominant follicle selection and follicle growth and function in cattle. Reproduction 123:837-845.

Sheldon, I. M., A. N. Rycroft, B. Dogan, M. Craven, J. J. Bromfield, A. Chandler, M. H. Roberts, S. B. Price, R. O. Gilbert, and K. W. Simpson. 2010. Specific strains of Escherichia coli are pathogenic for the endometrium of cattle and cause pelvic inflammatory disease in cattle and mice. PLoS ONE 5:e9192.

Silva, E., S. Leitão, T. Tenreiro, C. Pomba, T. Nunes, L. Lopes da Costa, and L. Mateus. 2009. Genomic and phenotypic characterization of Escherichia coli isolates recovered from the uterus of puerperal dairy cows. J. Dairy Sci. 92:6000-6010.

So, M., and B. J. McCarthy. 1980. Nucleotide sequence of the bacterial transposon Tn1681 encoding a heat-stable (ST) toxin and its identification in enterotoxigenic Escherichia coli strains. Proc. Natl Acad. Sci. USA 77:4011-4015.
Toni, F., L. Vincenti, A. Ricci, and Y. H. Schukken. 2015. Postpartum uterine diseases and their impacts on conception and days open in dairy herds in Italy. Theriogenology 84:1206-1214.

Wagener, K., T. Grunert, I. Prunner, M. Ehling-Schulz, and M. Drillich. 2014. Dynamics of uterine infections with Escherichia coli, Streptococcus uberis and Trueperella pyogenes in post-partum dairy cows and their association with clinical endometritis. Vet. J. 202:527-532.

Wagener, K., I. Prunner, H. Pothmann, M. Drillich, and M. EhlingSchulz. 2015. Diversity and health status specific fluctuations of intrauterine microbial communities in postpartum dairy cows. Vet. Microbiol. 175:286-293.

Werner, A., V. Suthar, J. Plontzke, and W. Heuwieser. 2012. Relationship between bacteriological findings in the second and fourth weeks postpartum and uterine infection in dairy cows considering bacteriological results. J. Dairy Sci. 95:7105-7114.

Williams, E. J., D. P. Fischer, D. E. Noakes, G. C. W. England, A. Rycroft, H. Dobson, and I. M. Sheldon. 2007. The relationship between uterine pathogen growth density and ovarian function in the postpartum dairy cow. Theriogenology 68:549-559.

Williams, E. J., D. P. Fischer, D. U. Pfeiffer, G. C. W. England, D. E. Noakes, H. Dobson, and I. M. Sheldon. 2005. Clinical evaluation of postpartum vaginal mucus reflects uterine bacterial infection and the immune response in cattle. Theriogenology 63:102-117.

Woodward, M. J., P. J. Carroll, and C. Wray. 1992. Detection of entero- and verocyto-toxin genes in Escherichia coli from diarrhoeal disease in animals using the polymerase chain reaction. Vet. Microbiol. 31:251-261.

Ye, C., and J. Xu. 2001. Prevalence of iron transport gene on pathogenicity-associated island of uropathogenic Escherichia coli in E. coli O157:H7 containing Shiga toxin gene. J. Clin. Microbiol. $39: 2300-2305$ 
Table A1. List of genes encoding 40 Escherichia coli virulence factors investigated in a study looking at the relationship between virulence factors and the occurrence of postpartum metritis in 371 Holstein dairy cows from 3 commercial herds

(a)

$\begin{array}{ll}\text { Adhesins } & \text { Adhesin involved in diffuse } \\ \text { Aida } & \text { adhen }\end{array}$

adherence,

$b m a E$

M-agglutinin major subunit

DNA sequence $\left(5^{\prime} \rightarrow 3^{\prime}\right)$

Amplified

product

Control

(bp)

strains

Reference

$\operatorname{clp} G-31 a$

CS31A Coli surface-associated

Eae

Fim H

F5 (K99)

F17

hra1

$P a a$

papC

$s f a A$

\section{Invasins}

Afa

afaDs

$i b e A$

Toxins

cnf1

Cnf2

$c d t B-1$

cvaC

East1

$h l y A$

HlyE
Intimin

Type 1 fimbriae

F5 fimbrial adhesin

F17a pili major sub-unit adhesin

Porcine A/E-associated gene

Pilus assembly, pap operon

Type S fimbriae major sub-unit

Dr antigen-specific adhesin operons

Invasin, AFA-8

Invasion protein

Cytotoxic necrotizing factor 1

Cytotoxic necrotizing factor 2

Cytolethal distending toxin I (b subunit)

Colicin V, conjugative plasmids

EaggEC heat-stable enterotoxin

Alpha-hemolysin (chromosome)

Hemolysine E
Hemagglutinin - non fimbrial
Forward (For): ACAGTATCATATGGAGCCA

For: ATGGCGCTAACTTGCCATGCTAT

Rev: AGGGGGACATATAGCCCCCTTC

For: GCACAATTACTGCTGATGCG

Rev: GTTATAAGTTACTGCCACGTTC

For: CATTATGGAACGGCAGAGGT

Rev: ATCTTCTGCGTACTGCGTTCA

For: TGCAGAACGGATAAGCCGTGG

Rev: GCAGTCACCTGCCCTCCGGTA

For: TGCGACTACCAATGCTTCTG

Rev: TATCCACCATTAGACGGAGC

For: TATCCTTGGAATACTGGCGG

Rev: CCAGTGGTGTAATCCGTGTT

For: TCACTTGCAGACCAGCGTTTC

Rev: GTAACTCACACTGCTGTCACCT

For: ATGAGGAACATAATGGCAGG

TCTGGTCAGGTCGTCAATAC

For: GACGGCTGTACTGCAGGGTGTGGCG

Rev: ATATCCTTTCTGCAGGGATGCAATA

For: CGGAGGAGTAATTACAAACCTGGCA

Rev: CTCCGGAGAACTGGGTGCATCTTAC

For: GGCAGAGGGCCGGCAACAGGC

Rev: CCCGTAACGCGCCAGCATCTC

For: GTTGAACTGAGTCTTAATACCAGTG

Rev: TGAGCATTCTCCGCTAACTGATAAT

For: AGGCAGGTGTGCGCCGCGTAC

Rev: TGGTGCTCCGGCAAACCATGC

For: TTATATAGTCGTCAAGATGGA

Rev: CACTAAGCTTTACAATATTGAC

For: GTCACAATAGACAATAATTTTCCG

Rev: TATCATACGGCAGGAGGAAGCACC

For (a1): AAATCACCAAGAATCATCCAGTTA

Rev (a2): AAATCTCCTGCAATCATCCAGTTTA

For (s1): GAAAGTAAATGGAATATAAATGTCCG

Rev (s2): GAAAATAAATGGAACACACATGTCCG

For: CACACACAAACGGGAGCTGTT

Rev: CTTCCCGCAGCATAGTTCCAT

For: TCGGATGCCATCAACACAGT

Rev: GTCGCGAGTGACGGCTTTGTAG

For: AGCCGGAACAGTTCTCTCAG

Rev: CCAGCATAACAGCCGATGTA

For: GAAACCGCAGATGGAGCATT

Rev: CGCCCGCAGCAATAGAATAG
ECL1033

ECL12344

$31 \mathrm{a}$

ECL6611

EDL933

ECL13316

ECL13256

ECL1033

ECL7805/ECL6611

ECL13256

94-279-171

ECL18162 (2H16)

ECL13455

ECL12312

ECL13455

S5

ECL9632

ECL12364

ECL7805

ECL7805

EDL933

Sgeleka et al., 2003

Chapman et al.,

2006

Girardeau et al.

1991

Beaudry et al.

1996

Chapman et al.

2006

Ojeniyi et al., 1994

Cid et al., 1999

Ewers et al., 2007

An et al., 1999

Daigle et al., 1994

Hilali et al., 2000

Goluszko et al.,

1997

Hilali et al., 2000

Ewers et al., 2007

Oswald et al., 1994

Oswald et al., 1994

Chapman et al.,

2006

Chapman et al.,

2006

Savarino et al.

1993

Sandhu et al. 1997

Silva et al., 2009 
Table A1 (Continued). List of genes encoding 40 Escherichia coli virulence factors investigated in a study looking at the relationship between virulence factors and the occurrence of postpartum metritis in 371 Holstein dairy cows from 3 commercial herds

\begin{tabular}{|c|c|c|c|c|c|}
\hline Virulence factor & Function & DNA sequence $\left(5^{\prime} \rightarrow 3^{\prime}\right)$ & $\begin{array}{l}\text { Amplified } \\
\text { product } \\
\text { (bp) }\end{array}$ & $\begin{array}{l}\text { Control } \\
\text { strains }\end{array}$ & Reference \\
\hline Sta & Thermo stable toxin a & $\begin{array}{l}\text { For: TCCCCTCTTTTAGTCAGTCAACTG } \\
\text { Rev: GCACAGGCAGGATTACAACAAAGT }\end{array}$ & 163 & ECL7805 & $\begin{array}{l}\text { So and McCarthy, } \\
1980\end{array}$ \\
\hline$S t b$ & Thermo stable toxin b & $\begin{array}{l}\text { For: GCAATAAGGTTGAGGTGAT } \\
\text { Rev: GCCTGCAGTGAGAAATGGAC }\end{array}$ & 368 & ECL7805 & Lortie et al., 1991 \\
\hline$L T$ & Thermo labile toxin & $\begin{array}{l}\text { For: TTACGGCGTTACTATCCTCTCTA } \\
\text { Rev: GGTCTCGGTCAGATATGTGATTC }\end{array}$ & 275 & ECL7805 & Furrer et al., 1990 \\
\hline stx 1 & Shiga-like toxin I & $\begin{array}{l}\text { For: TTAGACTTCTCGACTGCAAAG } \\
\text { Rev: TGTTGTACGAAATCCCCTCTG }\end{array}$ & 531 & ECL6611 & $\begin{array}{l}\text { Woodward et al., } \\
1992\end{array}$ \\
\hline stx2 & Shiga-like toxin II & $\begin{array}{l}\text { For: CTATATCTGCGCCGGGTCTG } \\
\text { Rev: AGACGAAGATGGTCAAAACG }\end{array}$ & 327 & ECL6611 & $\begin{array}{l}\text { Woodward et al., } \\
1992\end{array}$ \\
\hline $\begin{array}{l}\text { Capsule synthesis } \\
\text { kps } M-I I\end{array}$ & $\begin{array}{l}\text { Polysialic acid transport proteins, } \\
\text { group II (K1, K4, K5, K7, K12, } \\
\text { K30, K42, K92) }\end{array}$ & $\begin{array}{l}\text { For: GCGCATTTGCTGATACTGTTG } \\
\text { Rev: CATCCAGACGATAAGCATGAGC }\end{array}$ & 272 & $\mathrm{O} 1: \mathrm{K} 1$ & $\begin{array}{l}\text { Chapman et al., } \\
2006\end{array}$ \\
\hline $\begin{array}{l}\text { Iron acquisition } \\
\text { fep } C\end{array}$ & Ferric enterobactin transport & $\begin{array}{l}\text { For: TACCTGGATAATGCTGTCGG } \\
\text { Rev: ATGGTGTTGATGGGGCTGGC }\end{array}$ & 347 & EDL933 & Ye and $\mathrm{Xu}, 2001$ \\
\hline fyuA & $\begin{array}{l}\text { Yersinia siderophore receptor (ferric } \\
\text { yersiniabactin uptake) }\end{array}$ & $\begin{array}{l}\text { For: TGATTAACCCCGCGACGGGAA } \\
\text { Rev: CGCAGTAGGCACGATGTTGTA }\end{array}$ & 880 & ECL8985 & $\begin{array}{l}\text { Chapman et al., } \\
2006\end{array}$ \\
\hline $\operatorname{irp} 1$ & $\begin{array}{l}\text { Protein for biosynthesis of } \\
\text { yersiniabactin (peptide/polypeptide } \\
\text { synthetase) }\end{array}$ & $\begin{array}{l}\text { For: TGAATCGCGGGTGTCTTATGC } \\
\text { Rev: TCCCTCAATAAAGCCCACGCT }\end{array}$ & 240 & ECL12421 & Karch et al., 1999 \\
\hline irp2 & $\begin{array}{l}\text { Iron-repressible protein } \\
\text { (yersiniabactin synthesis) }\end{array}$ & $\begin{array}{l}\text { For: AAGGATTCGCTGTTACCGGAC } \\
\text { Rev: TCGTCGGGCAGCGTTTCTTCT }\end{array}$ & 286 & ECL12364 & Ewers et al., 2007 \\
\hline $\operatorname{iroN}$ & Novel catecholate siderophore & $\begin{array}{l}\text { For: AAGTCAAAGCAGGGGTTGCCCG } \\
\text { Rev: GACGCCGACATTAAGACGCAG }\end{array}$ & 665 & ECL12021 & $\begin{array}{l}\text { Chapman et al., } \\
2006\end{array}$ \\
\hline$i u c D$ & $\begin{array}{l}\text { Aerobactin (siderophore) synthesis } \\
\text { and receptor }\end{array}$ & $\begin{array}{l}\text { For: AAGTGTCGATTTTATTGGTGTA } \\
\text { Rev: CCATCCGATGTCAGTTTTCTG }\end{array}$ & 778 & ECL3110/ECL17088 & Herrero et al., 1988 \\
\hline iutA & $\begin{array}{l}\text { Ferric aerobactin receptor (iron } \\
\text { uptake/transport) }\end{array}$ & $\begin{array}{l}\text { For: GGCTGGACATCATGGGAACTGG } \\
\text { Rev: CGTCGGGAACGGGTAGAATCG }\end{array}$ & 300 & ECL1106 & $\begin{array}{l}\text { Chapman et al., } \\
2006\end{array}$ \\
\hline sitA & Putative iron transport gene & $\begin{array}{l}\text { For: AGGGGGCACAACTGATTCTCG } \\
\text { Rev: TACCGGGCCGTTTTCTGTGC }\end{array}$ & 608 & ECL12344 & $\begin{array}{l}\text { Rodriguez-Siek, et } \\
\text { al., } 2005\end{array}$ \\
\hline \multicolumn{6}{|c|}{ Additional virulence factors } \\
\hline iss & Increased serum survival & $\begin{array}{l}\text { For: ATCACATAGGATTCTGCCG } \\
\text { Rev: CAGCGGAGTATAGATGCCA }\end{array}$ & 309 & ECL12364 & Ewers et al., 2007 \\
\hline $\operatorname{malX}$ & PTS system for maltose and glucose & $\begin{array}{l}\text { For: GGACATCCTGTTACAGCGCGCA } \\
\text { Rev: TCGCCACCAATCACAGCCGAAC }\end{array}$ & 922 & ECL12021 & Ewers et al., 2007 \\
\hline neuC & p7 protein (polysialic acid synthesis) & $\begin{array}{l}\text { For: GGTGGTACATTCCGGGATGTC } \\
\text { Rev: AGGTGAAAAGCCTGGTAGTGTG }\end{array}$ & 676 & ECL12421 & Ewers et al., 2007 \\
\hline$T s h$ & $\begin{array}{l}\text { Temperature sensitive } \\
\text { hemagglutinin (hemoglobin } \\
\text { protease) }\end{array}$ & $\begin{array}{l}\text { For: GGTGGTGCACTGGAGTGG } \\
\text { Rev: AGTCCAGCGTGATAGTGG }\end{array}$ & 640 & ECL3110 & Dozois et al., 2000 \\
\hline Usp & Uropathogenic specific protein & $\begin{array}{l}\text { For: ACATTCACGGCAAGCCTCAG } \\
\text { Rev: AGCGAGTTCCTGGTGAAAGC }\end{array}$ & 440 & ECL12021 & Bauer et al., 2002 \\
\hline
\end{tabular}

